\title{
Observer Kalman Filter Identification of Suspen-Dome
}

\author{
Guojun Sun, ${ }^{1,2}$ Richard W. Longman, ${ }^{3}$ Raimondo Betti, ${ }^{4}$ Zhihua Chen, ${ }^{5}$ and Suduo Xue ${ }^{1,2}$ \\ ${ }^{1}$ College of Architecture and Civil Engineering, Beijing University of Technology, Beijing 100124, China \\ ${ }^{2}$ The Key Laboratory of Urban Security and Disaster Engineering, MOE, Beijing University of Technology, Beijing 100124, China \\ ${ }^{3}$ Department of Mechanical Engineering, Columbia University, New York, NY 10027, USA \\ ${ }^{4}$ Department of Civil Engineering and Engineering Mechanics, Columbia University, New York, NY 10027, USA \\ ${ }^{5}$ School of Civil Engineering, Tianjin University, Tianjin 300072, China \\ Correspondence should be addressed to Guojun Sun; sunny2369@163.com
}

Received 3 June 2016; Revised 8 October 2016; Accepted 19 December 2016; Published 12 January 2017

Academic Editor: Yuqiang Wu

Copyright (C) 2017 Guojun Sun et al. This is an open access article distributed under the Creative Commons Attribution License, which permits unrestricted use, distribution, and reproduction in any medium, provided the original work is properly cited.

\begin{abstract}
A number of Suspen-Dome structures have been built, but there is some difficulty in using experimental data to obtain good modal parameters, especially modal damping. In this paper, an ANSYS numerical simulation of the $35.4 \mathrm{~m}$ span Suspen-Dome is presented. Firstly, the natural vibration characteristics of Suspen-Dome and dynamic response under some random forces were obtained. Then the results of the numerical simulation established that 60 modes are sufficient for a reasonable dynamic model. This model is used to represent the Suspen-Dome dynamic behavior, and OKID is then used to try to identify a model from simulated data. A 400 order model generated from OKID is shown to contain the 60 modes from ANSYS and is shown to give good predictions of the dynamic behavior of Suspen-Dome. The results of this paper can confirm that it can be a very efficient tool for the identification of models of Suspen-Dome dynamics.
\end{abstract}

\section{Introduction}

With time, more long-spanned structures become needed to provide large open spaces for public activities. This calls for the development of long-spanned structures, such as cable structures, membrane structures, and steel-truss lattice structures. Among these, the Suspen-Dome has received much attention from engineers due to its artful and economic structural form. As a new kind of spatial structure, the Suspen-Dome structure [1-3] offers advantages over either the single-layer lattice dome or the tensegric network and is gaining increasing usage. Suspen-Dome is made of a singlelayer lattice dome, struts, and radial and latitudinal cables with appropriate prestresses. The ends of the struts hanging from the same ring of joints of the single-layer lattice dome are connected with the next ring of joints by radial cables and connected with each other by latitudinal cables. Struts and radial and latitudinal cables, being a tensegrity network, sustain vertical loads together with the single-layer lattice dome and, therefore, enable a more efficient and economic way of constructing large-span domes. There are more than twenty
Suspen-Dome projects in the world, most of them located in China [4]. It is very important to ensure an adequate level of safety of both new and existing Suspen-Dome structures against dynamic loadings such as wind and earthquakes. This can be achieved if the dynamic properties of the Suspen-Dome such as natural frequencies, mode shapes, and damping ratios are accurately determined. Modal analysis is a technique that estimates the dynamic characteristics (modal parameters) of a structure. These modal parameters serve as a basis for the finite element model updating, structural control, damage detection, condition assessment, and longterm health monitoring of the structure.

There are many operational modal identification methods to analyze measured data, including frequency domain, time domain, and time-frequency domain approaches. They were originally developed in more advanced mechanical and aerospace engineering disciplines, such as Peak-Picking (PP) [5], Frequency Domain Decomposition (FDD) [6, 7], Enhanced Frequency Domain Decomposition (EFDD) [8], Random Decrement based methods (RDT) [9], Natural Excitation Technique (NExT) [10], Eigensystem Realization 


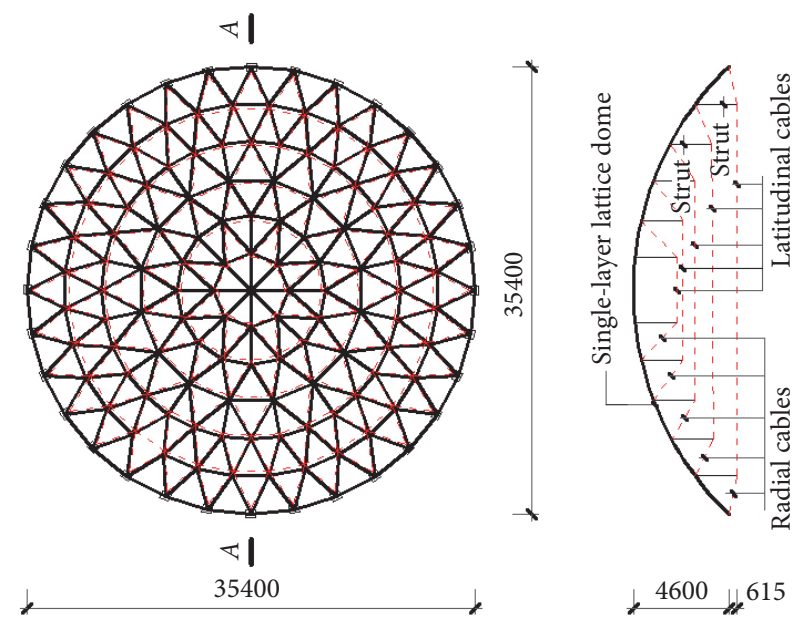

FIGURE 1: Structural layout (mm).

Algorithm (ERA) [11], Autoregressive Moving Average model (ARMA) [12], Bayesian statistical approach [13], wavelettype method [14, 15], and Hilbert-Huang Transform (HHT) method $[16,17]$.

Although modal identification methods are not new, the application of digital computers caused a dramatic increase of the practical possibilities of modal analysis. There is a clear merit in trying to transfer this technology into space structural engineering applications where we are dealing with problems which have a completely different scale, logistics, and rationale, compared with mechanical and aerospace engineering counterparts. In the context of the structure engineering discipline, for instance, Suspen-Dome structures are often complex, with many low frequency modes concentrated in a small frequency range. OKID is a system identification method whose development was motivated by modal testing of spacecraft structures, aiming to bypass time consuming frequency sweeps and to use time domain data without needing to convert to frequency domain $[18,19]$. It has proved to be numerically very efficient and robust with respect to measurement noise and even in the presence of mild nonlinearities. Many applications of this method in the area of structural mechanics and aerospace engineering have appeared $[20,21]$, and it is used here. The aim of this paper is to evaluate the applicability of OKID [22] to the identification of accurate dynamic models of a Suspen-Dome.

\section{Dynamic Test Model Used to Generate Simulated Data}

The Suspen-Dome model shown in Figure 1 is used to create simulated data, which are then used for numerical investigations of the ability to generate a good dynamic model of the structure from experimental tests, determining the influence of many factors such as the parameters involved in applying OKID as well as the influence of such choices as the number of sensors and actuators needed for effective dynamic testing. The span and rise of the dome are 35.4 and $4.6 \mathrm{~m}$, respectively.

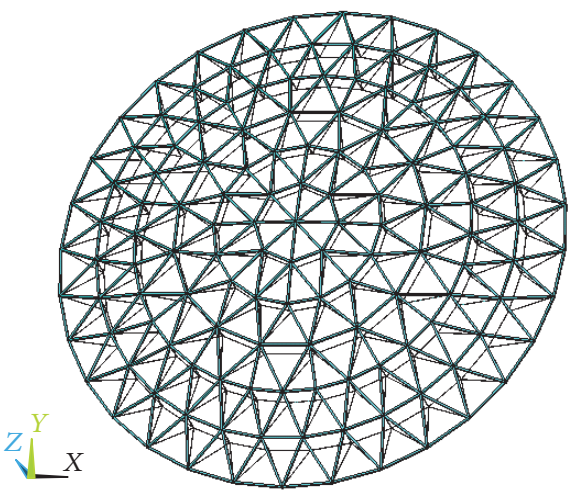

Figure 2: Finite element model.

To have a convenient cable arrangement, a single-layer lattice dome with parallel grid is adopted in the Suspen-Dome. Only one kind of steel tubing, $\Phi 140 \times 6$, is used for the members of the single-layer lattice dome. The members are connected with each other by welded hollow spherical joints, which are considered as rigid joints. Steel of Grade Q235B is adopted for all members and joint. The sectional areas are $269 \mathrm{~mm}^{2}$ for all the latitudinal cables and radial cables. Steel tube $\Phi 90 \times 4$ of Grade Q235B is adopted for the struts.

A finite element model of this structure is generated using commercial finite element software, ANSYS [23], as shown in Figure 2. BEAM4 was adopted to simulate all members of the upper dome, which is a uniaxial 3D element with tension, compression, torsion, and bending capabilities and has six degrees of freedom at each node. LINK8 was adopted to simulate all struts, which is a $3 \mathrm{D}$ spar element and is a uniaxial tension-compression element with three degrees of freedom at each node. LINK10 was adopted to simulate all cables, which is a $3 \mathrm{D}$ spar element having the unique feature of a bilinear stiffness matrix resulting in a uniaxial tensiononly element for our case, with three degrees of freedom at each node. 
TABLE 1: The first ten mode natural frequencies.

\begin{tabular}{lcccccccccc}
\hline Mode number & 1 & 2 & 3 & 4 & 5 & 6 & 7 & 8 & 9 & 10 \\
\hline Frequency $(\mathrm{Hz})$ & 3.4233 & 3.4233 & 3.7078 & 3.7078 & 3.7907 & 3.7907 & 3.8492 & 4.2520 & 4.2520 & 4.3399 \\
\hline
\end{tabular}

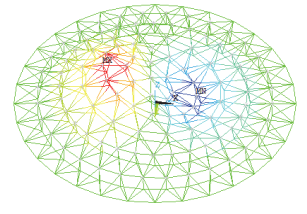

(a) 1st mode shape

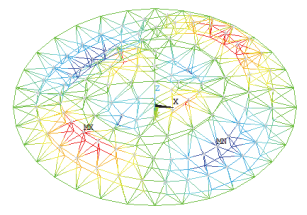

(f) 6th mode shape

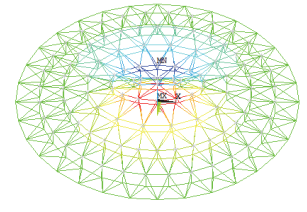

(b) 2nd mode shape

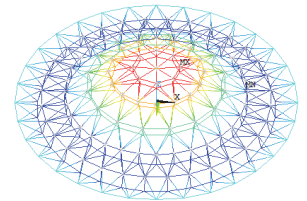

(g) 7th mode shape

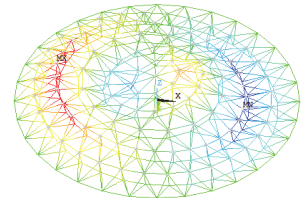

(c) 3rd mode shape

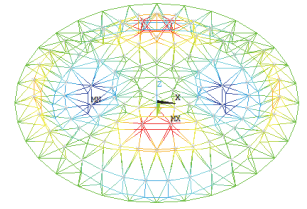

(h) 8th mode shape

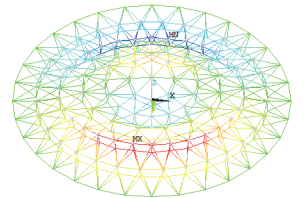

(d) 4th mode shape

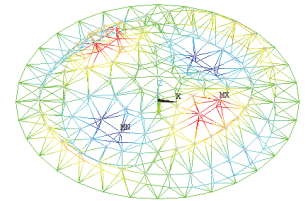

(i) 9th mode shape

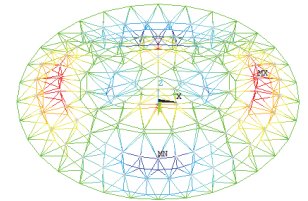

(e) 5 th mode shape

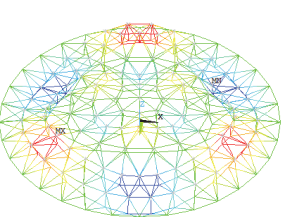

(j) 10th mode shape

Figure 3: The first ten mode shapes of the Suspen-Dome.

The Suspen-Dome was restrained vertically, radially, and latitudinally, at the 32 nodes of the outer ring of the singlelayer lattice dome. In order to simulate the dead load, MASS21 element was built on each node of the single-layer lattice dome and the added-mass is $2000 \mathrm{~kg}$. Materials for all the members and cables were assumed to be elastic. Young's modulus $E$ is $2.06 \times 10^{8} \mathrm{kN} / \mathrm{m}^{2}$ for all steel tubes and is $1.95 \times$ $10^{8} \mathrm{kN} / \mathrm{m}^{2}$ for the steel cables [24]. The material for the steel cables was set to not allow compression.

In order to prevent the cables from sagging under the load action, the latitudinal cables were pretensioned before applying the load to produce upward displacements of the dome. The pretension forces were applied as initial stresses, $60 \mathrm{kN}$ for the outermost latitudinal cables.

The subspace iteration method [25] for the dynamic characteristics was used. Here we display the first ten modal natural frequencies produced by the numerical analysis in Table 1 , and the corresponding mode shapes are given in Figure 3.

The dynamic response characteristics of the SuspenDome are complicated by the fact that the modal natural frequencies are very close to each other. The number of nodes used in the ANSYS model is large. In simulating experimental tests that generate data for identification, one must make appropriate choices for which nodes receive input excitations and which nodes will have sensors to record the response.

Figure 3 shows that the vibration directions are mainly in the vertical direction and the shapes of vibration modes are not only antisymmetric but also symmetric. The vibration mode shapes show a trend that the symmetry number is increased with the increase of vibration mode frequency. The location of the excitation cannot be limited to the center of the dome since this will excite only symmetric modes. Therefore, the input signal locations should be chosen as antisymmetry, such as four input signal locations shown in Figure 4. Actually, the other choice of input modes, which are antisymmetric, has no effect on the modal identification.

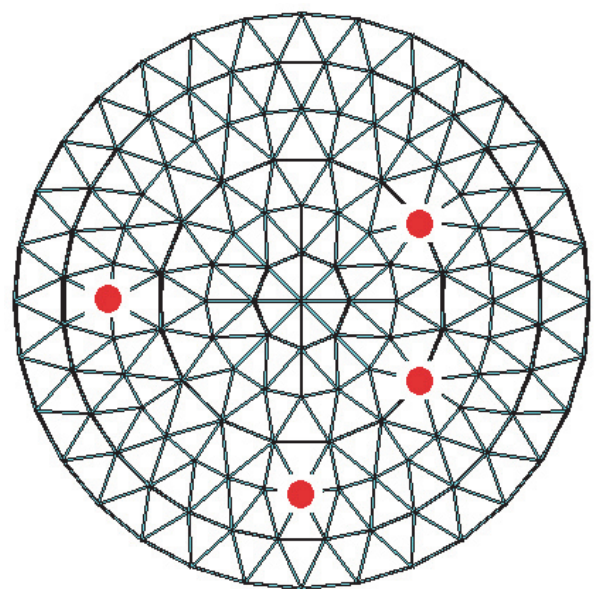

FIgURE 4: The location of input signals.

Although any real system has an infinite number of degrees of freedom, a limited subset of these is sufficient to capture the structural characteristics, and it is not necessary to make measurements of the response at all nodes. Based on the theoretical result of the first ten mode shapes of the Suspen-Dome and the symmetry of the Suspen-Dome structure, twenty-one node locations were selected as sensor locations, corresponding to about ten percent of the total number of nodes (shown in Figure 5).

OKID is a time domain system identification technique with the known input which should be sufficiently rich to excite all modes of interest. Four random input signals were generated uniformly distributed between zero and $1000 \mathrm{~N}$ and applied as vertical downward forces at the four input locations. The input update and the sensor sampling are done $100 \mathrm{~Hz}$, creating $200 \mathrm{~s}$ data records. The sensors record vertical displacement unless otherwise stated. In practical 


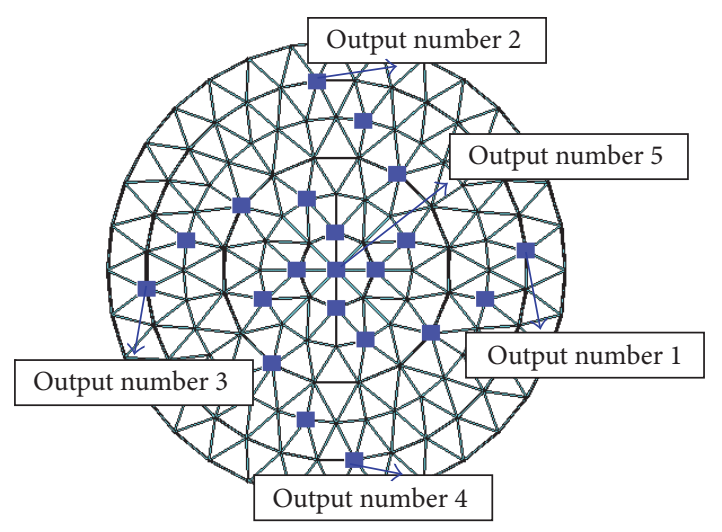

Figure 5: The location of output signals.

engineering design and Suspen-Dome, the viscous damping model was adopted. The modal damping ratios were assumed as 0.02 for all modes. The real eigenvectors were assumed as the natural frequency of vibration of the FEM. The numerical simulation of vibration time-history analysis was carried out using mode superposition method. In order to examine how many modes are sufficient to simulate the Suspen-Dome, 20 modes, 40 modes, 60 modes, and 80 modes were simulated. Comparison with using all 1038 modes showed that 60 modes produce essentially the same output histories, and this was chosen as our truth model. The first 1000 time steps of the response of the first five outputs located on outermost ring and the center are shown in Figure 6.

\section{Identification Results}

The total number of the Suspen-Dome nodes is 241. The nodes of single-layer lattice dome number 137 and 32 nodes of these are constrained to three directions, while the remaining elements are $3 \mathrm{D}$ beam element with 6 degrees of freedom. So the number of degrees of freedom of this layer lattice dome is $(137-32) \times 6+32 \times 3=726$. The number of nodes of the cable and strut is $241-137=104$, so it has $104 \times 3=312$ degrees of freedom. Therefore, the number of degrees of freedom of the whole structure is $726+312=1038$. The finite element model order is then $1038 \times 2=2076$.

When creating a model from data, one must pick a model order. Using OKID, model orders of 2100, 1200, 800, 400, 200,100 , and 50 were investigated. When the order of the system matrix was 400 or more, 60 structural modes can be identified. In other words, the 400 -order identified state space model can be used to compute the response of Suspen-Dome. A comparison of the 400-order identified state space model and the ANSYS world model shows essentially identical results with the input being that used in the identification. Figure 7 shows two of the outputs, and they are identical to graphical accuracy. The maximum variance of the difference of the outputs computed for 5 of the outputs was 5.47 times 10 to the -12 .

Due to the complexity of this Suspen-Dome, it is very difficult to obtain all modes, especially high-order modes. Theoretically, the order number of a system's model is supposed to be determined by the distribution of the singular values of the Hankel matrix. With noise free data, one can usually determine the true order of a finite order system from these singular values. In practice one has noise in data that creates what are called noise modes in the identified model, and these may not be easily distinguishable from true structural modes. Because of the complexity of the SuspenDome, numerical noise in the identification process can also produce noise modes or fake modes.

Methods have been developed to distinguish such fake modes from true structural modes, using a stabilization diagram. This diagram examines which modes have properties that do not change significantly when varying the order of the identified model, and these are considered to be true structural modes that are well identified from the data.

Modal parameter identification was carried out using OKID as implemented in [18] and using 20,000 simulated data time steps. Figure 8 presents an example stabilization diagram developed for many modes. We know from our truth model that the first 60 modes are enough to characterize the system response, so we look for the first 60 modes that appear to be stabilized as we change the order of the identified model. The diagram shows the first 10 stabilized modes and the 20th, 40th, and 60th stabilized modes that are modes for which the associated frequency is not significantly affected by change in model order as indicated by the vertical lines on the diagram. Figure 9 presents the first 10 modal frequencies and relative damping rations obtained from the stabilization diagram after deleting the fake modes and showing the insensitivity of the identified modes to the model order used in the identification.

The variation in every mode frequency is very small and the frequency estimates are steady. However, the relative variation in each mode damping ratio is larger than that for frequencies. As the order of the identified state space model is decreased, the number of fake modes decreases, but the estimation error increases. Hence, the procedure for obtaining good identification asks one to use a right order identified model, followed by use of the stabilization diagram to remove fake modes and reduce the model order. In the higher order identified state space model, the damping ratio estimates are steady. Therefore, the damping ratio estimates of a recognizable structural mode are determined with the steady frequency in the highest order structural model. All the results of the frequency estimates and damping ratio estimates from identified state space model are shown in Table 2. The largest error of the frequency estimates is $0.62 \%$, and the largest error of the damping ratio estimates is $2.10 \%$, in the first 10 modes. The largest error of the frequency estimates is again $0.62 \%$, and the largest error of the damping ratio estimates is $3.01 \%$, when considering the first 60 modes. The numerical and identification analysis provides a comprehensive investigation of the dynamic properties of the Suspen-Dome and indicates that OKID is capable of experimentally determining the dynamic properties of the Suspen-Dome.

In order to validate the 400 -order identified state space model further, a new input matrix was generated randomly by MATLAB. All output identification results from this 

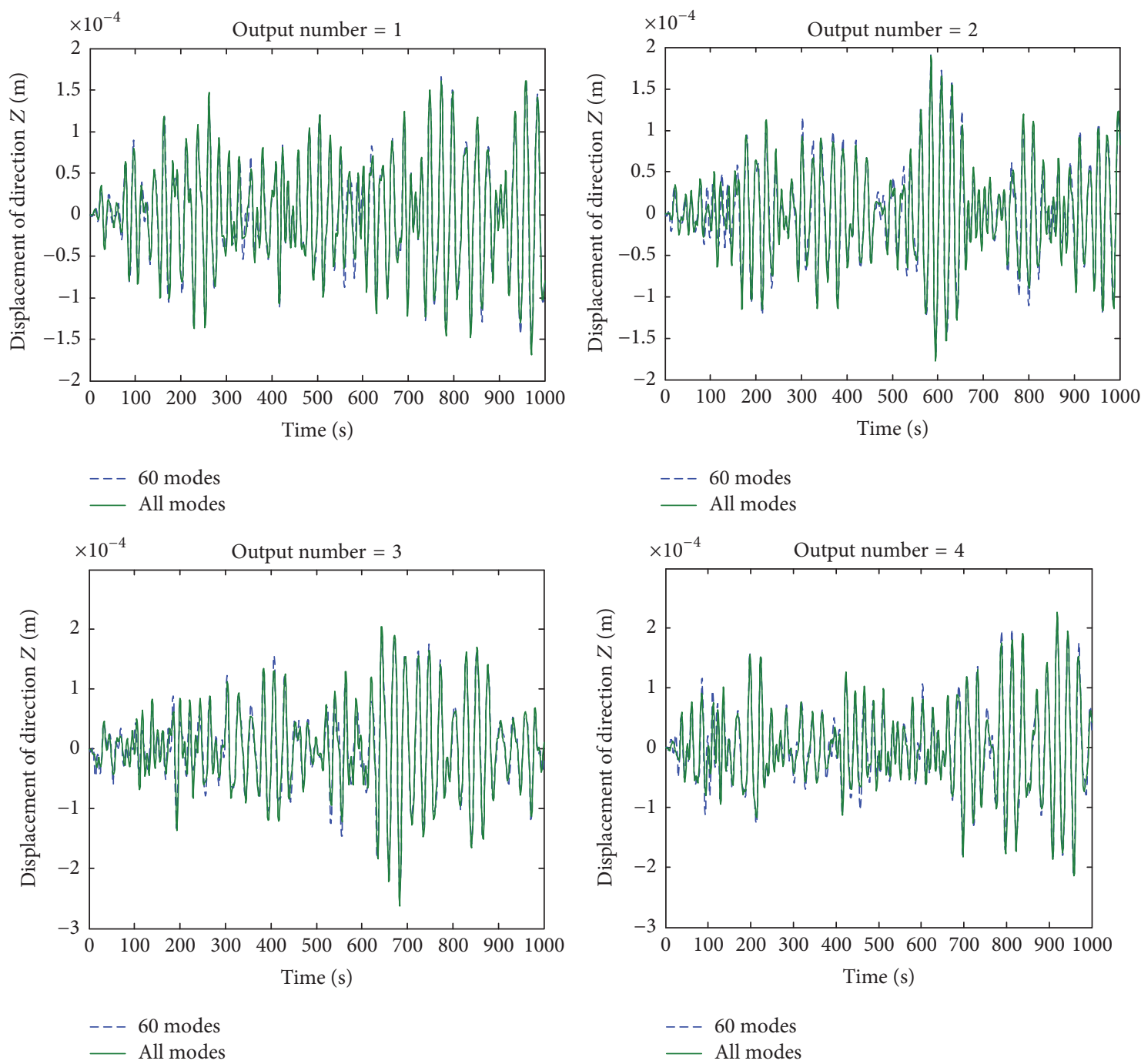

- All modes

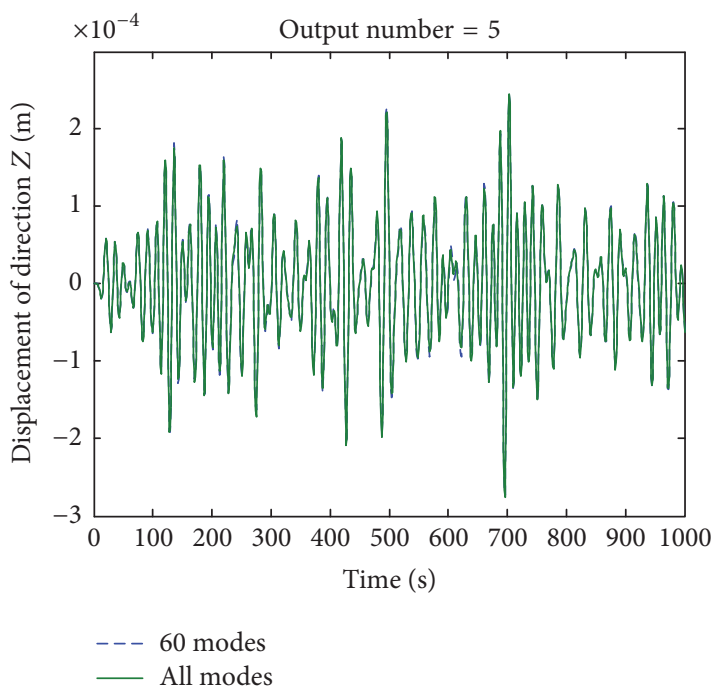

Figure 6: The first 1000 steps of response of the Suspen-Dome. 

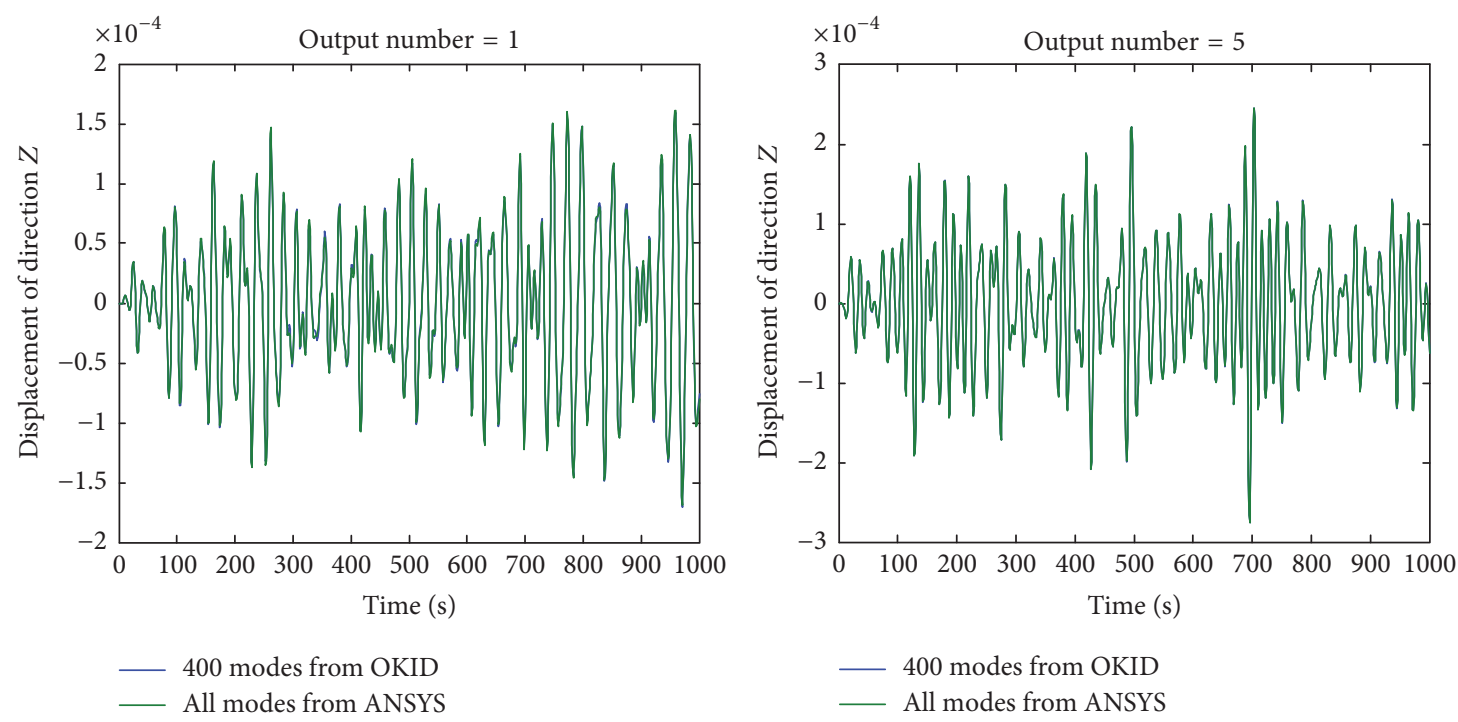

FIGURE 7: The first 1000 steps of response from 400-order model and ANSYS.

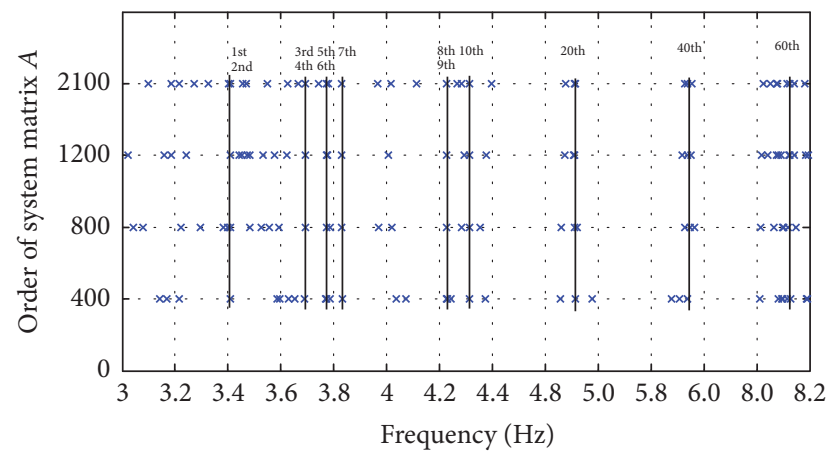

FIgURE 8: The stabilization diagram of Suspen-Dome.

400-order identified state space model are coincident with the ANSYS truth model output to graphical accuracy. Two example comparisons are shown in Figure 10. The maximum variances of the deviations of the outputs for the whole history are 7.25 times 10 to the -12 .

\section{Discussion}

In order to evaluate the applicability of OKID to the identification of accurate dynamic models of Suspen-Dome structures, three possible situations are considered here. The first situation, or state of the structure, is the intended design state of the structure. The second situation considers the dynamic behavior when the prestress of the outer latitudinal cables has lost $50 \%$ of the intended stress, resulting in modified structural internal forces and changes in the node locations. The third condition deletes the 32 struts and the 5 cables altogether, creating a single-layer lattice dome, while the node coordinates remain the same as the nodes of the single-layer lattice dome in Suspen-Dome.

Using the same method as Sections 3 and 4 that treated the design state of the structure, two new 400-order identified
TABLE 2: The results from identified state space model using displacement output signals.

\begin{tabular}{|c|c|c|c|c|}
\hline Model & Used & OKID & $\begin{array}{c}\text { Ref. } \\
\text { ANSYS }\end{array}$ & Error \\
\hline \multirow{14}{*}{$\begin{array}{l}\text { Freq. } \\
(\mathrm{Hz})\end{array}$} & 1 & 3.4101 & 3.4233 & $0.39 \%$ \\
\hline & 2 & 3.4101 & 3.4233 & $0.39 \%$ \\
\hline & 3 & 3.6911 & 3.7078 & $0.45 \%$ \\
\hline & 4 & 3.6911 & 3.7078 & $0.45 \%$ \\
\hline & 5 & 3.7729 & 3.7907 & $0.47 \%$ \\
\hline & 6 & 3.7729 & 3.7907 & $0.47 \%$ \\
\hline & 7 & 3.8306 & 3.8492 & $0.48 \%$ \\
\hline & 8 & 4.2268 & 4.2520 & $0.59 \%$ \\
\hline & 9 & 4.2268 & 4.2520 & $0.59 \%$ \\
\hline & 10 & 4.3132 & 4.3399 & $0.62 \%$ \\
\hline & $\vdots$ & $\vdots$ & $\vdots$ & $\vdots$ \\
\hline & 20 & 4.9120 & 4.9541 & $0.85 \%$ \\
\hline & 40 & 5.9373 & 5.9985 & $1.02 \%$ \\
\hline & 60 & 8.1247 & 8.2275 & $1.25 \%$ \\
\hline \multirow{14}{*}{$\begin{array}{l}\text { Damp. } \\
(\%)\end{array}$} & 1 & 2.0380 & 2.0000 & $1.86 \%$ \\
\hline & 2 & 2.0380 & 2.0000 & $1.86 \%$ \\
\hline & 3 & 2.0398 & 2.0000 & $1.95 \%$ \\
\hline & 4 & 2.0397 & 2.0000 & $1.95 \%$ \\
\hline & 5 & 2.0403 & 2.0000 & $1.98 \%$ \\
\hline & 6 & 2.0403 & 2.0000 & $1.98 \%$ \\
\hline & 7 & 2.0406 & 2.0000 & $1.99 \%$ \\
\hline & 8 & 2.0427 & 2.0000 & $2.09 \%$ \\
\hline & 9 & 2.0425 & 2.0000 & $2.08 \%$ \\
\hline & 10 & 2.0429 & 2.0000 & $2.10 \%$ \\
\hline & $\vdots$ & $\vdots$ & $\vdots$ & $\vdots$ \\
\hline & 20 & 2.0448 & 2.0000 & $2.19 \%$ \\
\hline & 40 & 2.0460 & 2.0000 & $2.25 \%$ \\
\hline & 60 & 2.0621 & 2.0000 & $3.01 \%$ \\
\hline
\end{tabular}

state space models are identified for the two additional situations, the Suspen-Dome and dome, respectively. Table 3 


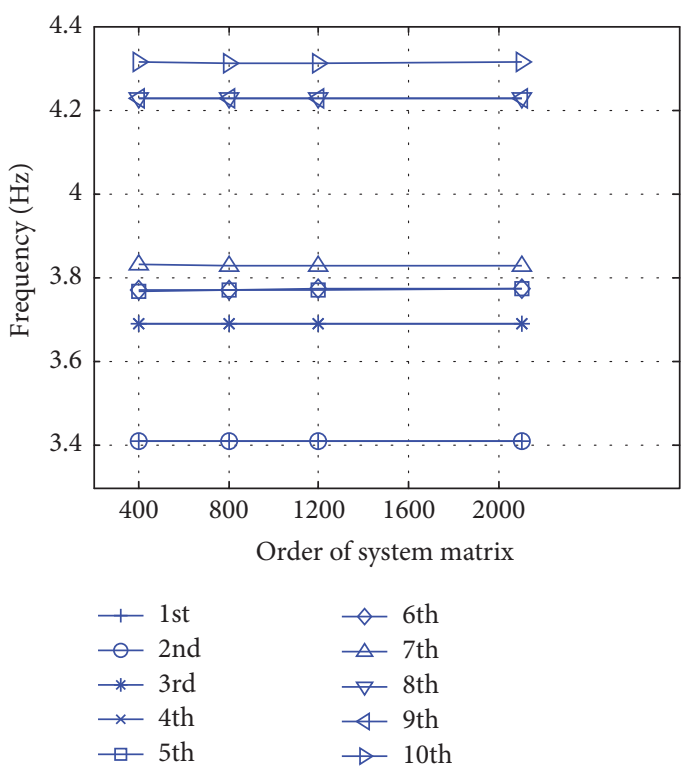

(a) The variation in the frequency

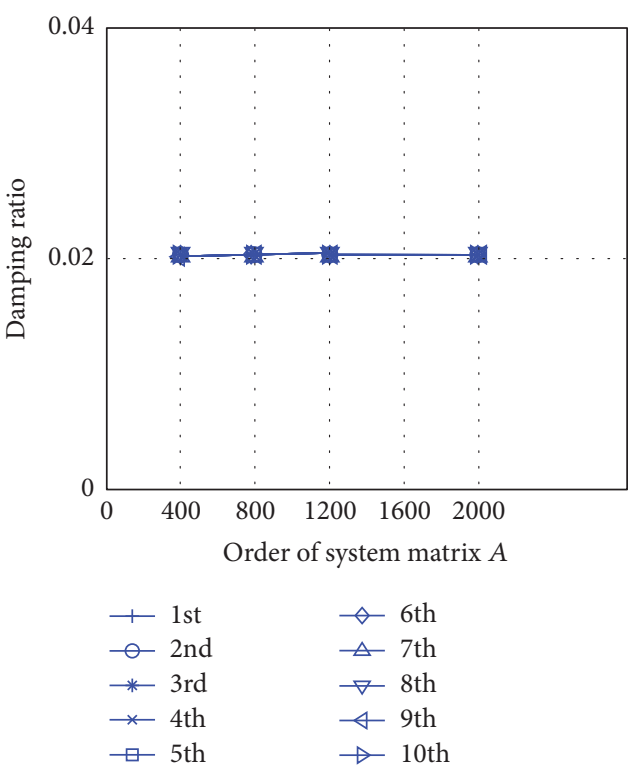

(b) The variation in the damping ratio

FIGURE 9: The estimates from OKID.

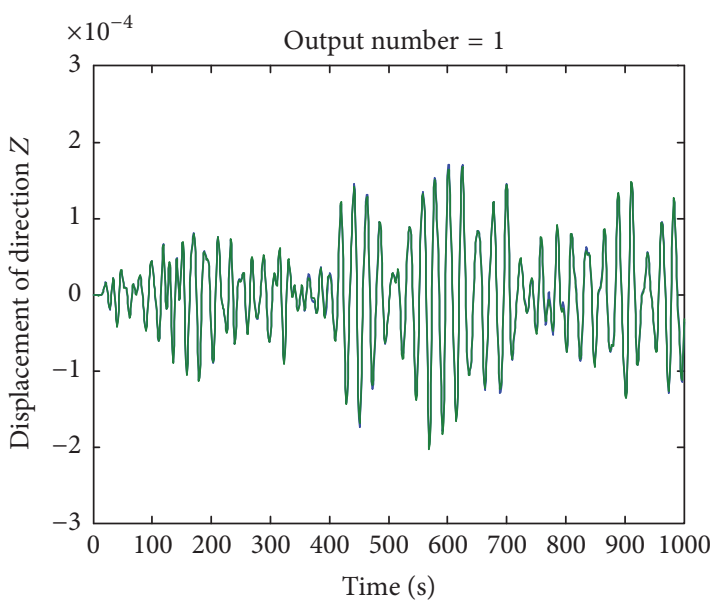

— 400 modes from OKID — All modes from ANSYS

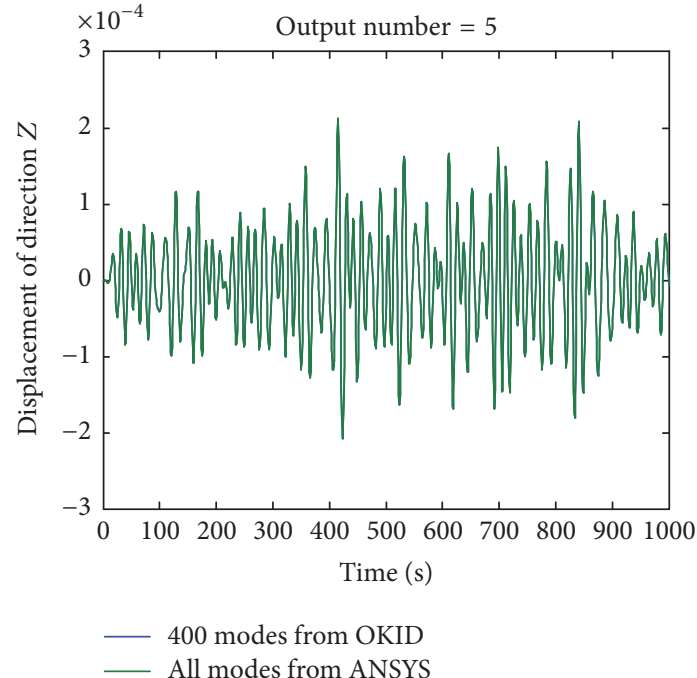

Figure 10: The new first 1000 steps of response.

shows the first ten mode frequency estimates and associated damping ratio estimates from the identified state space models obtained using 21 displacement output signals. States 1 and 2 show very little difference in the identified frequencies and damping. In the state 1 , the largest error of the frequency estimates is $0.62 \%$, and the largest error of the damping ratio estimates is $2.10 \%$. In the state 2 , the largest error of the frequency estimates is again $0.62 \%$, and the largest error of the damping ratio estimates is also the same $2.10 \%$. In state 3 , the largest error of the frequency estimates is $0.52 \%$, and the largest error of the damping ratio estimates is $2.60 \%$. These results indicate that OKID is capable of handling identification of Suspen-Dome dynamics. For state 3, without the cables and struts, the accuracy of frequency estimates and damping ratio estimates from identified state space model is higher. When the cable force is decreased, the frequency of each mode of the Suspen-Dome increases infinitesimally. All of the mode frequencies with the cables and struts removed are smaller than in the other two states. Also, the rigidity of the Suspen-Dome is greater than the traditional single-layer lattice dome.

\section{Conclusions}

In this paper, the OKID method has been applied to the identification of the dynamics of Suspen-Dome. OKID is a general algorithm for identification of linear models from input-output data, but the original motivation was for modal 
TABLE 3: The results from identified state space model of three different states.

\begin{tabular}{|c|c|c|c|c|c|c|c|c|c|c|}
\hline \multirow[b]{2}{*}{ Model } & \multirow[b]{2}{*}{ Used } & \multicolumn{3}{|c|}{ State 1} & \multicolumn{3}{|c|}{ State 2} & \multicolumn{3}{|c|}{ State 3} \\
\hline & & OKID & $\begin{array}{c}\text { Ref. } \\
\text { ANSYS }\end{array}$ & Error & OKID & $\begin{array}{c}\text { Ref. } \\
\text { ANSYS }\end{array}$ & Error & OKID & $\begin{array}{c}\text { Ref. } \\
\text { ANSYS }\end{array}$ & Error \\
\hline \multirow{10}{*}{$\begin{array}{l}\text { Freq. } \\
(\mathrm{Hz})\end{array}$} & 1 & 3.4101 & 3.4233 & $0.39 \%$ & 3.3990 & 3.4120 & $0.38 \%$ & 3.3524 & 3.3649 & $0.37 \%$ \\
\hline & 2 & 3.4101 & 3.4233 & $0.39 \%$ & 3.3990 & 3.4120 & $0.38 \%$ & 3.3524 & 3.3649 & $0.37 \%$ \\
\hline & 3 & 3.6911 & 3.7078 & $0.45 \%$ & 3.6863 & 3.7030 & $0.45 \%$ & 3.4923 & 3.5065 & $0.41 \%$ \\
\hline & 4 & 3.6911 & 3.7078 & $0.45 \%$ & 3.6863 & 3.7030 & $0.45 \%$ & 3.5978 & 3.6132 & $0.43 \%$ \\
\hline & 5 & 3.7729 & 3.7907 & $0.47 \%$ & 3.7695 & 3.7873 & $0.47 \%$ & 3.5978 & 3.6132 & $0.43 \%$ \\
\hline & 6 & 3.7729 & 3.7907 & $0.47 \%$ & 3.7695 & 3.7873 & $0.47 \%$ & 3.7012 & 3.7181 & $0.46 \%$ \\
\hline & 7 & 3.8306 & 3.8492 & $0.49 \%$ & 3.8192 & 3.8377 & $0.48 \%$ & 3.7014 & 3.7181 & $0.45 \%$ \\
\hline & 8 & 4.2268 & 4.2520 & $0.60 \%$ & 4.2211 & 4.2462 & $0.59 \%$ & 3.9151 & 3.9357 & $0.53 \%$ \\
\hline & 9 & 4.2268 & 4.2520 & $0.60 \%$ & 4.2211 & 4.2462 & $0.59 \%$ & 3.9158 & 3.9357 & $0.51 \%$ \\
\hline & 10 & 4.3132 & 4.3399 & $0.62 \%$ & 4.3140 & 4.3408 & $0.62 \%$ & 3.9676 & 3.9875 & $0.50 \%$ \\
\hline \multirow{10}{*}{$\begin{array}{l}\text { Damp. } \\
(\%)\end{array}$} & 1 & 2.0380 & 2.0000 & $1.86 \%$ & 2.0380 & 2.0000 & $1.86 \%$ & 2.0376 & 2.0000 & $1.85 \%$ \\
\hline & 2 & 2.0381 & 2.0000 & $1.87 \%$ & 2.0380 & 2.0000 & $1.86 \%$ & 2.0381 & 2.0000 & $1.87 \%$ \\
\hline & 3 & 2.0398 & 2.0000 & $1.95 \%$ & 2.0398 & 2.0000 & $1.95 \%$ & 2.0386 & 2.0000 & $1.89 \%$ \\
\hline & 4 & 2.0398 & 2.0000 & $1.95 \%$ & 2.0398 & 2.0000 & $1.95 \%$ & 2.0391 & 2.0000 & $1.92 \%$ \\
\hline & 5 & 2.0403 & 2.0000 & $1.98 \%$ & 2.0404 & 2.0000 & $1.98 \%$ & 2.0392 & 2.0000 & $1.92 \%$ \\
\hline & 6 & 2.0403 & 2.0000 & $1.98 \%$ & 2.0402 & 2.0000 & $1.97 \%$ & 2.0397 & 2.0000 & $1.95 \%$ \\
\hline & 7 & 2.0406 & 2.0000 & $1.99 \%$ & 2.0406 & 2.0000 & $1.99 \%$ & 2.0416 & 2.0000 & $2.04 \%$ \\
\hline & 8 & 2.0425 & 2.0000 & $2.08 \%$ & 2.0425 & 2.0000 & $2.08 \%$ & 2.0533 & 2.0000 & $2.60 \%$ \\
\hline & 9 & 2.0426 & 2.0000 & $2.09 \%$ & 2.0425 & 2.0000 & $2.08 \%$ & 2.0420 & 2.0000 & $2.06 \%$ \\
\hline & 10 & 2.0429 & 2.0000 & $2.10 \%$ & 2.0430 & 2.0000 & $2.10 \%$ & 2.0187 & 2.0000 & $0.93 \%$ \\
\hline
\end{tabular}

testing of structures. The results here confirm that it can be a very efficient tool for the identification of models of SuspenDome dynamics. The following conclusions can be drawn.

Because of the symmetry of the Suspen-Dome structure, there are many identified mode natural frequencies that are close to each other, but there is also a wide frequency range for important modes, making the dynamic characteristics of Suspen-Dome extremely complex. The vibration of SuspenDome is mainly vertical, and the first four vibration modes are seen to be antisymmetric while the next six are symmetric. The vibration mode shapes show a trend that is as the symmetry number is increased the mode frequency increases. The frequencies values from OKID and ANSYS indicate that the rigidity of Suspen-Dome is somewhat insensitive to cable force and greater than the traditional single-layer lattice dome.

Applying OKID to the Suspen-Dome involves the following steps. (1) Starting with a large order for the model to be identified, use input-output data to obtain a model, which can produce the output signal from the input signal with good accuracy. (2) Obtain the frequency estimates and damping ratio estimates from each mode number from the eigenvalues of the system matrix. (3) Set up a stabilization diagram of this structure and separate the true structural modes from noise modes or poorly identified modes. (4) In accordance with the frequencies from Step (2), obtain the damping ratio from the high-order mode identification. Simulation results demonstrate that this method can pick up the correct system order and produce good estimates of the modal parameters.

\section{Competing Interests}

The authors declare that there is no conflict of interests regarding the publishing of this paper.

\section{Acknowledgments}

This work is partially supported by National Natural Science Foundation of China (51408016) and China Postdoctoral Science Foundation (2014M550580).

\section{References}

[1] M. Kawaguchi, A. Masaru, and I. Tatemichi, "Design, tests and realization of 'suspen-dome' system," Journal of the International Association for Shell and Spatial Structures, vol. 40, no. 3, pp. 179-192, 1999.

[2] Z. H. Zhang, Q. S. Cao, and S. L. Dong, "Structural design of a practical suspendome," Advanced Steel Construction, vol. 4, no. 4, pp. 321-338, 2008.

[3] Z. X. Guo, K. R. Shi, B. Luo, Q. Tian, J. Wu, and S. Bi, "Lifting installation and prestressed cable construction of suspendome roof for Wuhan Gymnasium," Frontiers of Architecture and Civil Engineering in China, vol. 2, no. 1, pp. 87-92, 2008. 
[4] Z. H. Chen, Suspen-Dome Structure, Science Press, Beijing, China, 2010.

[5] R. W. Clough and J. Penzien, Dynamics of Structures, McGrawHill, New York, NY, USA, 1975.

[6] R. Brincker, L. Zhang, and P. Andersen, "Modal identification of output-only systems using frequency domain decomposition," Smart Materials and Structures, vol. 10, no. 3, pp. 441-445, 2001.

[7] F. Magalhães, Á. Cunha, and E. Caetano, "Dynamic monitoring of a long span arch bridge," Engineering Structures, vol. 30, no. 11, pp. 3034-3044, 2008.

[8] R. Brincker, C. Ventura, and P. Andersen, "Damping estimation by frequency domain decomposition," in Proceedings of the 19th International Modal Analysis Conference, pp. 698-703, Kissimmee, Fla, USA, May 2001.

[9] A. Kareem and K. Gurley, "Damping in structures: its evaluation and treatment of uncertainty," Journal of Wind Engineering and Industrial Aerodynamics, vol. 59, no. 2-3, pp. 131-157, 1996.

[10] J. M. W. Brownjohn, F. Magalhaes, E. Caetano, and A. Cunha, "Ambient vibration re-testing and operational modal analysis of the Humber Bridge," Engineering Structures, vol. 32, no. 8, pp. 2003-2018, 2010.

[11] D. M. Siringoringo and Y. Fujino, "System identification of suspension bridge from ambient vibration response," Engineering Structures, vol. 30, no. 2, pp. 462-477, 2008.

[12] Y. L. Pi and N. C. Mlckleborough, "Modal identification of vibrating structures using ARMA model," Journal of Engineering Mechanics, vol. 115, no. 10, pp. 2232-2250, 1989.

[13] J. Beck, "System identification methods applied to measured seismic response," in Proceedings of the 11th World Conference on Earthquake Engineering, Acapulco, Mexico, June 1996.

[14] T. Kijewski and A. Kareem, "Wavelet transforms for system identification in civil engineering," Computer-Aided Civil and Infrastructure Engineering, vol. 18, no. 5, pp. 339-355, 2003.

[15] M. Ülker-Kaustell and R. Karoumi, "Application of the continuous wavelet transform on the free vibrations of a steel-concrete composite railway bridge," Engineering Structures, vol. 33, no. 3, pp. 911-919, 2011.

[16] Y. L. Xu, S. W. Chen, and R. C. Zhang, "Modal identification of Di Wang building under Typhoon York using the HilbertHuang transform method," Structural Design of Tall Buildings, vol. 12, no. 1, pp. 21-47, 2003.

[17] J. N. Yang, Y. Lei, S. Lin, and N. Huang, "Identification of natural frequencies and dampings of in situ tall buildings using ambient wind vibration data," Journal of Engineering Mechanics, vol. 130, no. 5, pp. 570-577, 2004.

[18] J.-N. Juang, M. Phan, L. G. Horta, and R. W. Longman, "Identification of observer/Kalman filter Markov parameters: theory and experiments," Journal of Guidance, Control, and Dynamics, vol. 16, no. 2, pp. 320-329, 1993.

[19] J. N. Juang, Applied System Identification, Prentice Hall, 1994.

[20] C.-W. Chen, J.-K. Huang, M. Phani, and J.-N. Juang, "Integrated system identification and state estimation for control of flexible space structures," Journal of Guidance, Control, and Dynamics, vol. 15, no. 1, pp. 88-95, 1992.

[21] M. Phan, L. G. Horta, J.-N. Juang, and R. W. Longman, "Improvement of observer/Kalman filter identification (OKID) by residual whitening," Journal of Vibration and Acoustics, vol. 117, no. 2, pp. 232-239, 1995.

[22] M. Phan, "Observer/Kalman filter identification (OKID): stepby-step guide and references," A Matlab-Based System Identification Software Package, Department of Mechanical and Aerospace Engineering, Princeton University, 1997.
[23] ANSYS, Users' Manual, Swanson Analysis Systems Inc, Houston, Pa, USA, 1995.

[24] CECS, "Technical specification for pre-stressed steel structures," Tech. Rep. CECS212:2006, CECS, Beijing, China, 2006.

[25] H.-J. Jung, M.-C. Kim, and I.-W. Lee, "An improved subspace iteration method with shifting," Computers \& Structures, vol. 70, no. 6, pp. 625-633, 1999. 


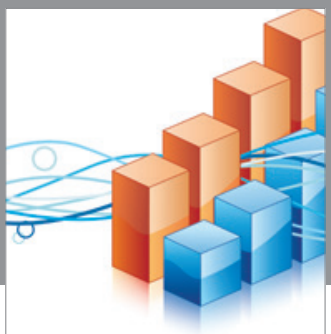

Advances in

Operations Research

vatem alat4

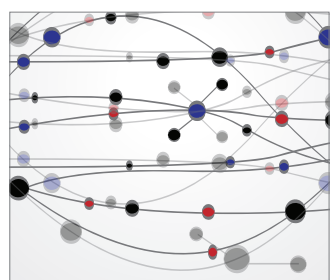

\section{The Scientific} World Journal
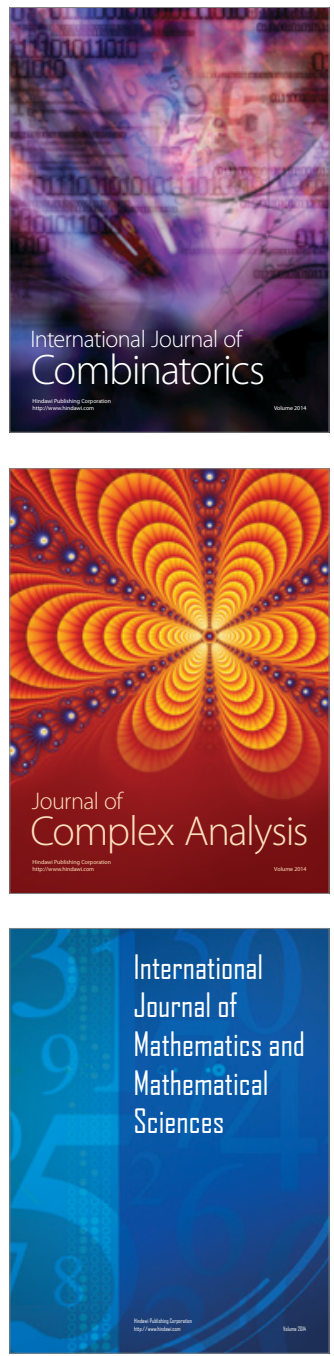
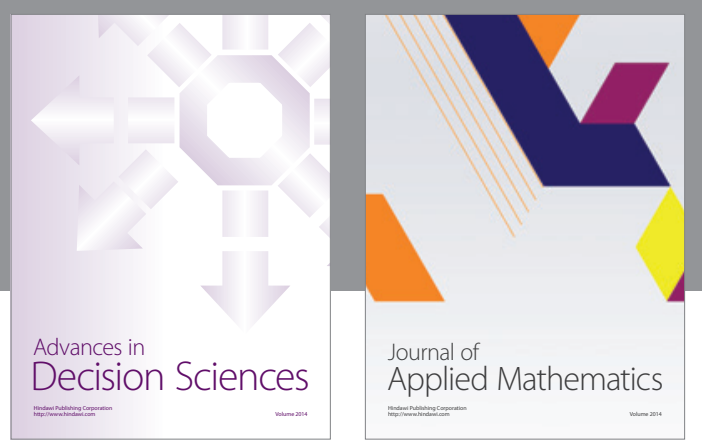

Algebra

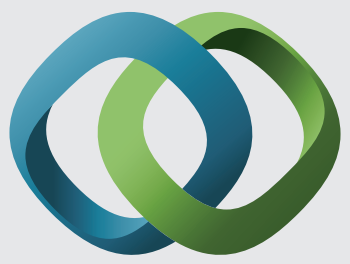

\section{Hindawi}

Submit your manuscripts at

https://www.hindawi.com
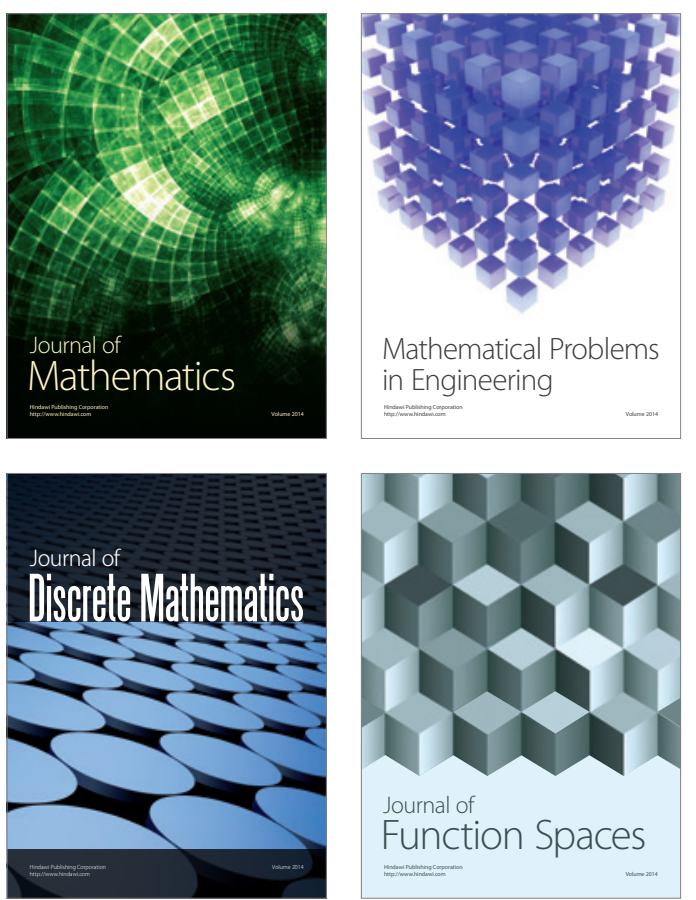

Mathematical Problems in Engineering
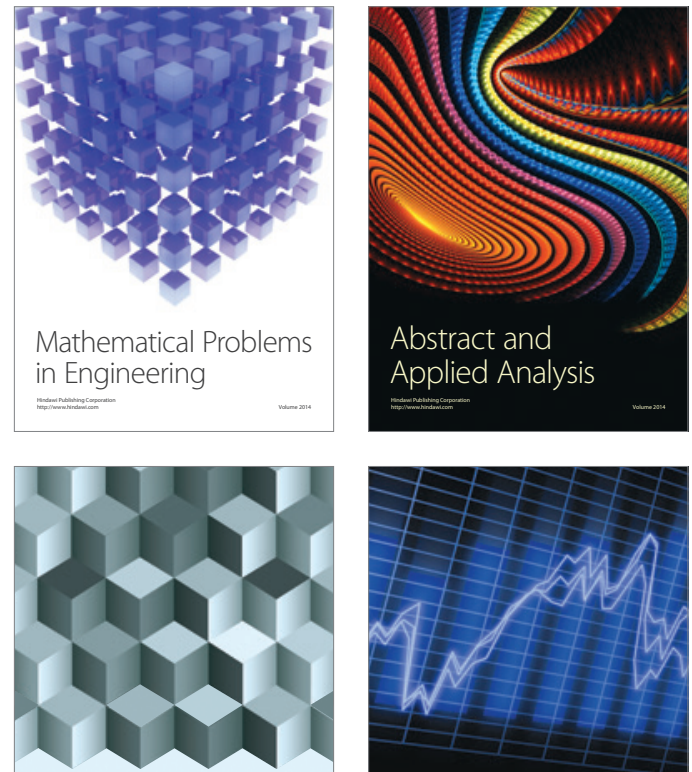

Journal of

Function Spaces

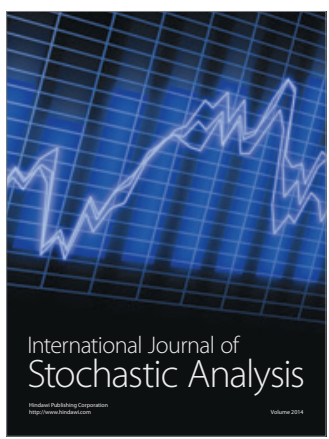

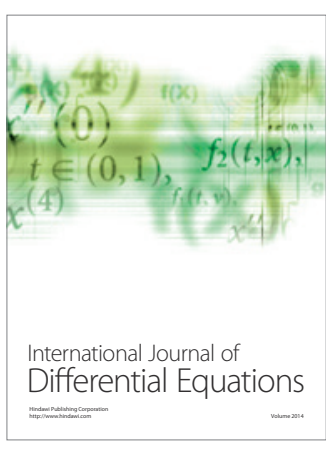
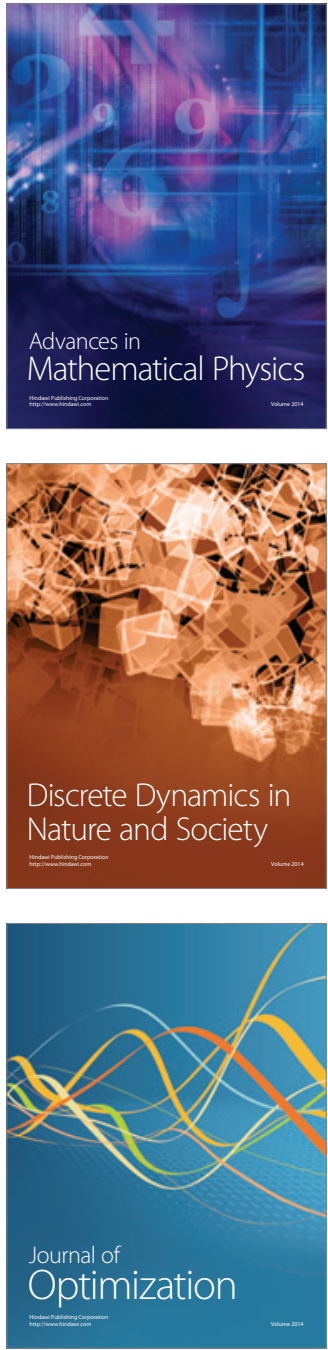